Available online at http://journal.stkip-andi-matappa.ac.id/index.php/histogram/index Histogram: Jurnal Pendidikan Matematika 4(2)., 2020, 538 - 544

\title{
PENGARUH PENDEKATAN REALISTIC MATHEMATICS EDUCATION (RME) TERHADAP PRESTASI BELAJAR MATEMATIKA SISWA SMP
}

\section{Sri Yulianti ${ }^{*}$}

${ }^{1}$ Universitas Islam Ogan Komering Ilir Kayuagung

* Corresponding Author. Email: sriyulianti82@gmail.com

Received: 10 Agustus 2020; Revised: 15 September 2020 ; Accepted: 30 September 2020

\begin{abstract}
ABSTRAK
Penelitian ini bertujuan untuk mengetahui pengaruh pembelajaran model Realistic Mathematics Education (RME) terhadap prestasi belajar matematika siswa kelas VII di SMP Ba'it Al-Quran Kayuagung tahun ajaran 2019/2020. Metode penelitian adalah eksperimen semu (quasi experiment). Sampel penelitian adalah kelas VII Cairo dan kelas VII Mekah dengan menggunakan populasi studi. Data dikumpulkan dengan tes tertulis yaitu tes essay. Untuk menganalisis data, dilakukan uji prasyarat yaitu normalitas dan homogenitas dan uji hipotesis yaitu uji-t. Hasil penelitian menunjukkan bahwa nilai tes akhir pada signifikansi 0,000 dan t-hitung lebih besar daripada t-tabel. Dengan kata lain, $H_{0}$ ditolak. yang artinya pendekatan Realistic Mathematics Education (RME) berpengaruh terhadap prestasi belajar matematika siswa SMP Ba'it Al-Quran Kayuagung. Disimpulkan, terdapat perbedaan prestasi belajar antara siswa yang menggunakan pendekatan Realistic Mathematics Education dengan siswa yang menggunakan pendekatan Teacher Centered .

Kata kunci: Pendekatan pembelajaran, RME, prestasi belajar
\end{abstract}

\section{ABSTRACT}

This study aims to determine the influence of realistic mathematics education (RME) model learning on the achievements of mathematics students in grade VII at SMP Ba'it Al-Quran Kayuagung school year 2019/2020. The research method is quasi experiment. The research samples are grade VII Cairo and class VII Mecca using the study population. The data is collected by written test which is essay test. To analyze the data, a prerequisite test of normality and homogeneity was conducted and a hypothesis test was conducted, namely the ttest. The results showed that the final test score at 0.000 and $t$-count was greater than the $t$ table. In other words, HO is rejected. which means realistic mathematics education (RME) approach affects the achievements of mathematics learning students of SMP Ba'it Al-Quran Kayuagung. In conclusion, there are differences in learning achievement between students who use realistic mathematics education approach and students who use Teacher Centered approach.

Keywords: Learning Approach, RME, Learning Achievement

How to Cite: Yulianti, S. (2020). Pengaruh Pendekatan Realistic Mathematics Education (RME) Terhadap Prestasi Belajar Matematika Siswa SMP. Histogram: Jurnal Pendidikan Matematika, 4(2), 538 - 544, doi: http://dx.doi.org/10.31100/histogram.v4i2.736

Permalink/DOI: http://dx.doi.org/10.31100/histogram.v4i2.736

\section{PENDAHULUAN}

Setiap siswa Sekolah Dasar sampai Perguruan Tinggi telah mempelajari matematika dan mengimplementasikannya di dalam kehidupan sehari-hari (Heni, 2019; Akbar, 2018; Bernard, 2019; Sugandi, 2019). Himpunan diajarkan pada level awal ketika memasuki SMP. Himpunan merupakan sekelompok benda yang jelas (Murniasih, 2016).

Copyright $₫$ 2020, THE AUTHOR (S). This article distributed under the CC-BY-SA-license. 


\section{Histogram: Jurnal Pendidikan Matematika, 4 (2), 2020 - 539 \\ Sri Yulianti ${ }^{*}$}

Dengan kata lain, siswa diharapkan dapat memahami cara membedakan mana anggota himpunan dan yang bukan.

Akan tetapi dilihat pada realitas yang ada, hasil belajar siswa masih dikategorikan masih tergolong rendah hal ini mengindikasikan bahwa pendekatan guru dalam mengajar matematika kurang efektif.

Diantara indikator kefektifan dalam pembelajaran matematika yakni hasil pembelajaran. Jika prestasi siswa tinggi, ini menandakan bahwa proses pembelajaran matematika sudah efektif dan jika hasilnya cenderung rendah, maka menunjukkan adanya ketidakefektifan dalam pembelajaran matematika. Menurut Zulkardi (2005), padatnya kurikulum, kurang tepatnya penggunaan media pembelajaran, kurang sesuainya strategi dan metode pembelajaran, buruknya sistem evaluasi, kurangnya kemampuan guru memotivasi belajar siswa, dan atau penggunaan pendekatan pembelajaran yang konvensional menyebabkan hasil belajar matematika yang rendah.

Berdasarkan uraian diatas, dapat diasumsikan bahwa salah satu faktor kurangnya mutu dalam pembelajaran matematika yaitu ketidaktepatan pendidik dalam menentukan pendekatan pembelajaran saat menyampaikan materi di kelas. Metode belajar dalam proses belajar mengajar adalah merupakan faktor penting yang mempengaruhi hasil belajar di tingkat Sekolah Menengah Pertama karena materi yang diajarkan dalam matematika masih bersifat tidak nyata sedangkan siswa memiliki daya fikir yang nyata.

Dari sekian banyak pendekatan, pendekatan RME dapat diaplikasikan guna memperbaiki hasil belajar siswa dengan menghadirkan sesuatu yang nyata. Agus (2017:78) menjelaskan bahwa dengan RME siswa mampu berfikir lebih cepat dan kreatif, menggunakan realita serta lingkungan untuk memecahkan masalah agar mudah menguasai matematika dengan tepat. Dengan kata lain, pendekatan pembelajaran ini memanfaatkan situasi "dunia nyata" sehingga materi pembelajaran dan pengalaman siswa dapat dikaitkan. Freudenthal (dalam Ozdemir, 2017:407) juga menyatakan "a main way of Realistic Mathematics Education (RME) is a concept about mathematics outcome by persons actions and a way of mathematizing fact and it is feasible even that of mathematizing mathematics". Dengan kata lain, pokok penting dari pendekatan pembelajara ini yaitu ide tentang ilmu hitung yang merupakan buatan kegiatan makhluk hidup dan cara realitas matematika.

Objek matematika bersifat tidak nyata seperti buah pikiran, pendapat, rancangan, tanda-tanda, dan koordinasi hubungan antara komponen-komponen dalam populasi (himpunan). Oleh sebab itu, guru sebaiknya menggunakan pendekatan yang 


\section{Histogram: Jurnal Pendidikan Matematika, 4 (2), 2020 - 540 \\ Sri Yulianti ${ }^{*}$}

tepat sehingga dapat meningkatkan pemahaman siswa. Secara psikologis, siswa SMP memiliki tingkat perkembangan mental pada tahap pemahaman nyata dan, belum mampu berfikir yang tidak nyata. Selanjutnya, pemilihan pendekatan pembelajaran matematika yang sesuai dengan pertambahan usia siswa harus dipertimbangkan.

Bersumber pada penjelasan diatas, maka disusunlah rumusan masalah "Apakah terdapat hasil belajar yang berbeda antar siswa yang menggunakan pendekatan pembelajaran RME dengan pendekatan pembelajaran konvensional?"

\section{METODOLOGI PENELITIAN}

Dalam penelitian ini menggunakan quasi ekperimental sebagai jenis penelitian. Menurut Arikunto (2014:9), ekperimen merupakan salah satu cara untuk mendapatkan hubungan antara dua faktor yang rancang peneliti dengan menghilangkan faktor-faktor lain yang tidak sesuai. Suter (2012, p.63) menjelaskan bahwa penelitian kuasi eksperimental adalah penelitian yang melibatkan penggunaan variabel independen yang dimanipulasi (intervensi) tanpa penugasan acak peserta ke kelompok, melemahkan kemampuan peneliti untuk menemukan hubungan sebab dan akibat.

Nonequivalent control group design digunakan dalam penelitian ini. Pengaruh perlakuan terhadap prestasi belajar matematika siswa adalah $\left(\mathrm{O}_{\mathrm{E} 2}-\mathrm{O}_{\mathrm{E} 1}\right)-\left(\mathrm{O}_{\mathrm{K} 2}-\mathrm{O}_{\mathrm{K} 1}\right)$.

Tabel 1. Desain Penelitian Eksperimen

\begin{tabular}{cccc}
\hline Kelas & Tes Awal & Perlakuan & Tes Akhir \\
\hline Eksperimen & $\mathrm{O}_{\mathrm{E} 1}$ & $\mathrm{X}$ & $\mathrm{O}_{\mathrm{E} 2}$ \\
\hline Kontrol & $\mathrm{O}_{\mathrm{K} 1}$ & - & $\mathrm{O}_{\mathrm{K} 2}$
\end{tabular}

(Sumber: Sugiyono, Tahun: 2013)

Penjelasan :

$\mathrm{O}_{\mathrm{E} 1} \quad$ : tes awal kelas eksperimen

$\mathrm{O}_{\mathrm{K} 1} \quad$ : tes awal kelas kontrol

$\mathrm{X} \quad$ : perlakuan (pendekatan RME)

$\mathrm{O}_{\mathrm{E} 2} \quad$ : tes akhir kelas eksperimen

$\mathrm{O}_{\mathrm{K} 2} \quad$ : tes akhir kelas kontrol

\section{HASIL DAN PEMBAHASAN}

Setelah dilakukan pengolahan data, maka statistik deskriptif didapatkan. Kemudian, data tersebut dihitung menggunakan Software SPSS 22 for Windows. Deskripsi data hasil tes awal dan akhir disajikan di tabel 2. 
Histogram: Jurnal Pendidikan Matematika, 4 (2), 2020 - 541 Sri Yulianti ${ }^{*}$

Tabel 2. Deskripsi Nilai Tes awal dan Tes Akhir

\begin{tabular}{ccccc}
\hline \multirow{2}{*}{ Skor Statistik } & \multicolumn{2}{c}{ Kelas Eksperimen } & \multicolumn{2}{c}{ Kelas Kontrol } \\
\cline { 2 - 5 } & $\begin{array}{c}\text { Tes } \\
\text { Awal }\end{array}$ & $\begin{array}{c}\text { Tes } \\
\text { Akhir }\end{array}$ & $\begin{array}{c}\text { Tes } \\
\text { Awal }\end{array}$ & Tes Akhir \\
\hline Jumlah Siswa (n) & 22 & 22 & 22 & 22 \\
\hline Skor Tertinggi & 77 & 92 & 81 & 89 \\
\hline Skor Terendah & 54 & 80 & 55 & 67 \\
\hline Skor rata - rata & 67,640 & 85,550 & 66,640 & 77,550 \\
\hline Variansi & 43,960 & 12,830 & 49,470 & 28,830 \\
\hline Simpangan baku & 6,630 & 3,582 & 7,034 & 5,369
\end{tabular}

(Sumber: Data Primer, Tahun: 2020)

Pada Tabel 2 terlihat kenaikan kemahiran penalaran pada kedua kelas setelah diagihkan perlakuan. Mean tes akhir kelas yang diberi perlakuan meningkat. Uji normalitas, uji homogenitas, dan uji kemampuan awal dilakukan terlebih dahulu sebelum uji hipotesis.

Tabel 3. Hasil Uji Normalitas

\begin{tabular}{llccc}
\hline \multirow{2}{*}{ Kelas } & \multicolumn{3}{c}{ Kolmogorov-smirnov } \\
\cline { 3 - 5 } & \multicolumn{1}{c}{ Tes Awal Eksperimen } & 0,144 & 22 & 0,200 \\
& \begin{tabular}{l} 
(RME) \\
\cline { 2 - 4 }
\end{tabular} & & & \\
\cline { 2 - 5 } $\begin{array}{l}\text { Hasil Belajar } \\
\text { Siswa }\end{array}$ & Tes Akhir & 0,121 & 22 & 0,200 \\
& Eksperimen (RME) & & & \\
\cline { 2 - 5 } & Tes Awal Kontrol & 0,112 & 22 & 0,200 \\
\cline { 2 - 5 } & Tes Akhir Kontrol & 0,166 & 22 & 0,118 \\
\hline
\end{tabular}

(Sumber: Data Primer, Tahun: 2020)

Nilai signifikansi pada kedua tes di kedua kelas yang disajikan pada Tabel 3 menandakan lebih dari $\alpha=0,05$. Hal ini menyatakan data sampel berasal dari subjek penelitian memiliki distribusi normal. 


\section{Histogram: Jurnal Pendidikan Matematika, 4 (2), 2020 - 542 \\ Sri Yulianti ${ }^{*}$}

Berdasarkan penghitungan uji homogenitas, didapatkan bahwa nilai kedua tes pada kedua kelas tersebut bernilai signifikan tinggi dari $\alpha=0,05$. Ini mengidentifikasikan data yang diperoleh dari sampel mempunyai variansi yang homogen.

Berdasarkan uji kemampuan awal, dapat dimaknai bahwa kedua kelas memiliki kemampuan awal yang sama. Lihat Tabel 4.

Tabel 4. Hasil Uji Kemampuan Awal

\begin{tabular}{ccc}
\hline \multicolumn{3}{c}{ Ujian Kesamaan Rata-rata } \\
\hline Signifikansi & Keputusan & Kesimpulan \\
\hline 0,630 & $\mathrm{H}_{0}$ diterima & $\begin{array}{c}\text { rata-rata kemampuan } \\
\text { awal sama }\end{array}$ \\
\end{tabular}

(Sumber: Data Primer, Tahun: 2020)

Dari perhitungan uji-t yang tidak berpasangan diperoleh t-hitung 5,813, t-tabel 2,01, dan t-hitung lebih tinggi dibanding t-tabel $(5,813>2,01)$, sehingga di simpulkan bahwa terdapat perbedaan signifikan prestasi belajar matematika siswa kelas VII SMP Bait Al-Quran Kayuagung setelah diberi perlakuan Realistic Mathematics Education (RME).

Tabel 5. Hasil Independen Uji-t

\begin{tabular}{lccccc}
\hline Uji-t-untuk kesamaan rata-rata & & \\
\hline $\begin{array}{r}\text { Sig. (2- } \\
\text { pihak) }\end{array}$ & $\begin{array}{c}\text { Perbeda } \\
\text { an Rat- } \\
\text { rata }\end{array}$ & $\begin{array}{c}\text { Std. Error } \\
\text { perbedaan }\end{array}$ & t & df \\
\hline Asumsi variansi sama & 0,000 & 8,000 & 1,376 & 5,813 & 42 \\
\hline (Sumber: Data Primer, Tahun: 2020) & & &
\end{tabular}

Berdasarkan analisis Tabel 5 diperoleh perbedaan yang signifikan pada implementasi pembelajaran RME terhadap prestasi belajar siswa. Hasil ini relevan dengan Zulkardi (2009), Widyastuti, dkk (2014), dan Muncarno,dkk (2018), ditinjau dari model pembelajaran, desain penelitian, dan hasil penghitungan menghasilkan perbedaan yang signifikan dalam penerapan pendekatan RME terhadap kemampuan ilmu hitung siswa. Dengan kata lain, pendekatan RME lebih efektif menaikkan nilai matematika siswa kelas VII SMP Ba'it Al-Quran Kayuagung. 


\section{Histogram: Jurnal Pendidikan Matematika, 4 (2), 2020 - 543 \\ Sri Yulianti ${ }^{*}$}

\section{KESIMPULAN DAN SARAN}

Setelah di laksakanakan penelitian dan analisi data diperoleh hasil yaitu prestasi belajar mata pelajaran matematika terhadap siswa yang mendapat perlakuan tidak lebih tinggi daripada siswa yang tidak mendapat perlakuan. Terlihat dari hasil uji-t dimana hasil t-hitung lebih besar daripada t-tabel. Ini menunjukkan terdapat perbedaan yang siginifikan untuk nilai siswa yang diajarkan dengan pendekatan RME dibandingkan dengan siswa yang diajar secara konvensional. Selanjutnya, diharapkan guru matematika mengetahui konsep pendekatan pembelajaran RME sehingga dapat lebih mengoptimalkan prestasi belajar di berbagai macam materi pembelajaran.

\section{UCAPAN TERIMA KASIH}

Terima kasih disampaikan ke Kementerian Pendidikan dan Kebudayaan dan pihak sekolah dari SMP Bait Al-Quran Kayuagung Sumatera Selatan yang telah mendukung sehingga penelitian ini dapat terlaksana.

\section{DAFTAR PUSTAKA}

Agus, R.N. 2016. Efektivitas Pembelajaran Matematika Melalui Pendekatan Realistic Mathematics Education (RME) dengan Pemecahan masalah Ditinjau dari Gaya Belajar Siswa. JIP STKIP Kusuma Negara. Vol. 7, No. 2.

Akbar, P.,Bernard,M.,\& Sugandi, A.I. 2018. Analisis Kemampuan pemecahan masalah dan disposisi matematik siswa kelas XI SMA Putra Juang dalam materi Peluang. Jurnal Cendikia: Jurnal Pendidikan Matematika, 2 (1), 144 - 153

Heni, T. 2019. Meningkatkan Motivasi dan hasil Belajar Matematika dengan menggunakan model Realistic Matematics Education (RME) Materi Himpunan. Journal On Education, Vol 2 No. 1, 161-166

Ozdemir, B. G. 2017. Mathematical Practices In A Learning Environment Designed by Realistic Mathematics Education: Teaching Experiment About Cone and Pyramid. European Journal of Education Studies. Vol. 5 No. 2.

Muncarno dkk. 2018. Pengaruh Pendekatan RME terhadap hasil belajar matematika. Jurnal Aksioma. Vol 7. No.1.

Murniasi, T.R.,Ferdiani, R.D.,\&Fayeldi, T. 2016. Media smart diagram venn untuk meningkatkan pemahaman konsep siswa pada materi himpunan. Math Didactic, 2(2), $70-76$

Sugiyono. 2013. Metode Penelitian Pendidikan. Bandung. Alfa-beta.

Suharsimi Arikunto. 2014. Prosedur Penelitian Suatu Pendekatan Praktik. Jakarta : Rineka Cipta.

Suter, W. N. (2012). Introduction to educational research; A critical thinking approach. London: SAGE Publications Inc. 


\title{
Histogram: Jurnal Pendidikan Matematika, 4 (2), 2020 - 544
}

\author{
Sri Yulianti ${ }^{*}$
}

Widyastuti, N. S, dkk. 2014. Pengaruh Pendidikan Matematika Realistik Indonesia (PMRI) terhadap Pemahaman Konsep Dan Berpikir Logis Siswa. Jurnal Prima Edukasia. Vol 2, No. 2.

Zulkardi. 2005. Pendidikan Matematika di Indonesia, Permasalahan dan Upaya Penyelesainnya. Palembang : Percetakan Unsri.

Zulkardi, dkk. 2009. Pengembangan Materi Pembelajaran Bilangan Berdasarkan Pendidikan Matematika Realistik untuk Siswa Kelas V Sekolah Dasar. Jurnal Pendidikan Matematika. Vol. 3, No. 1. 